\title{
JOGOS DIGITAIS PARA APRENDIZAGEM MULTIDISCIPLINAR: EXPERIÊNCIAS E PROSPECÇÕES
}

\section{ARTIGO ORIGINAL}

COSTA, Anselmo Augusto Fernandes ${ }^{1}$

COSTA, Anselmo Augusto Fernandes. Jogos digitais para aprendizagem multidisciplinar: Experiências e prospecções. Revista Científica Multidisciplinar Núcleo do Conhecimento. Ano 05, Ed. 08, Vol. 13, pp. 116-126. Agosto de 2020. ISSN: 2448-0959, Link de

acesso: https://www.nucleodoconhecimento.com.br/educacao/aprendizagem$\underline{\text { multidisciplinar }}$

\section{RESUMO}

Considerando o modelo de educação seguido no Brasil, conteudista, onde as práticas pedagógicas seguem um fluxo focado em apenas abordar o conteúdo curricular, limitando o aluno a apenas fazer tarefas, anotar, mantendo-o em uma situação cômoda, ao mesmo tempo limitada, onde a apatia e a falta de interação professoraluno e aluno-aluno são fatos, pretende-se com este artigo apresentar problemas e propor alternativas que têm dado certo em uma escola estadual localizada no município de Belém do Pará, região norte do Brasil, onde os recursos são escassos, porém com a boa vontade de alguns profissionais da educação, estimulando a aprendizagem baseada em jogos, adaptando estes jogos a livros didáticos, explorado o potencial dos alunos (com alguma deficiência ou não), aplicando Metodologias Ativas, objetiva-se com este trabalho apresentar resultados de interesse e engajamento deles em aprender por meio de jogos de aprendizagem onde há

1 Pós Graduado em Metodologia do Ensino de Língua Inglesa pela UFAMUniversidade Federal do Amazonas. Pós Graduado em Educação Especial pela UCDB-Universidade Católica Dom Bosco. 
competição, interação e sinergia em sala de aula. Apresentar-se-á neste trabalho o cenário, as abordagens, os sujeitos e objetos desta investigação, instrumentos de coleta, análise de dados levantados pelo autor e pelos alunos participantes, além do reconhecimento por parte da comunidade científica da relevância dos jogos de aprendizagem para a Educação Básica.

Palavras-Chave: Práticas, jogos, interação, abordagens.

\section{INTRODUÇÃO}

Jogos são essenciais para o aprendizado, é algo explicado cientificamente. Se você observar os animais, especialmente os mamíferos durante sua mais tenra infância, eles vivem a brincar, a interagir uns com os outros; criam instintivamente suas próprias regras, as quebram e quando a situação foge do controle, a mamãe gato faz uma interpelação para que a situação não fique instável. Assim, essas habilidades são essenciais para que estes filhotes futuramente aprendam a caçar, a conviver em grupos, constituir família, enfim, e estabelecerem-se em sociedade. Assim somos nós, humanos; precisamos brincar, jogar, desafiar e sermos desafiados. Claro que sempre respeitando regras e aprendendo a perder e a ganhar, de acordo com a sorte e o desempenho de cada um. Se respeitarmos a definição de Hernandez (2006), a primeira finalidade de uma visão integrada da educação é a que favorece a criação de experiências de aprendizagem com sentido e ao tê-la, o estudante, os professores e os membros da comunidade se envolvem apaixonadamente no processo de aprender". A prática dos jogos em sala de aula favorecem o engajamento, o envolvimento, o trabalho em time, a cooperação e consequentemente a aprendizagem torna-se mais ativa pois durante o processo do jogar, uns ensinam os outros, correm riscos, envolvem-se e comprometem-se ainda mais com o aprendizado. Assim, propõe-se com este trabalho dispor dos recursos utilizados para jogos, uma enquete com o resultado do nível de satisfação que os alunos de algumas turmas da escola terão com relação à aplicação de jogos em sala adaptados ao material didático, no caso o livro de inglês e de que forma alunas com deficiência auditiva podem engajarse em jogos em libras. Apresentaremos também o resultado de um trabalho exposto 
por 3 alunos da rede pública de ensino, sendo 2 surdas deste grupo, direcionado a aprendizagem por meio de jogos durante uma Feira de Ciência e Tecnologia realizada em Igarapé Miri, a FEICITI durante o mês de novembro de 2019.

\section{DESENVOLVIMENTO}

Professores de diversas disciplinas são peritos em adaptar materiais diversos para o ensino, especialmente os de idiomas e mais especificamente de língua inglesa e o propósito é sempre o mesmo: o professor tentar fazer o aluno aprender por meio de alguma habilidade de aprendizagem: auditiva, visual, musical, sinestésica, entre outras. É neste contexto que entram os jogos de diversão e os jogos de aprendizagem; eles acabam tornando-se relevantes, pois se praticados moderadamente, acionam a dopamina, substância química localizada no córtex pré-frontal, que nos fornece sensação de prazer e recompensa, entretanto é a mesma substância liberada por usuários de drogas. Então, liberar ou não a dopamina? Depende... em diversas experiências em sala de aula, percebeu-se o entusiasmo dos alunos em jogar; havia realmente um engajamento, uma vontade de participar tanto em situações de jogos manuais, quanto com os digitais: no Power Point, WordWall, elo (Ensino de Línguas on-line). Os jogos sempre acionam a substância responsável pela recompensa, aquele grande final, ou a hora da verdade ou no ápice de quem ganha ou quem perde. Após o uso do livro didático, o jogo funciona como um termômetro para ver o que eles aprenderam e verificar, assim, se eles estavam prontos para as avaliações escritas. Nesse ponto a dopamina é boa! O prazer em jogar e principalmente a sensação de ganhar estimulá-los ainda mais a estudar, pois assim o grande interessado (a mente consciente) fornece o seguinte comando para sua mente subconsciente: "preciso estudar para jogar e assim, talvez ganhar". Pronto! Encontramos aí um objetivo!

Vale ressaltar que o presente trabalho inclui um processo formado por jogos de diversão e jogos de aprendizagem e não incluem a Gamificação que é um estudo ainda mais abrangente e mais elaborado. Portanto, será abordado em um outro artigo. 


\subsection{INICIANDO O QUEBRA-CABEÇA}

Após uma reunião, chegou-se a um consenso sobre como as questões seriam montadas. Seria difícil usar o Google Forms, pois nem todos tinham acesso a suas contas ou internet, decidiu-se então criar fichas com perguntas sobre o nível de satisfação de 4 jogos realizados em sala de aula durante as aulas de inglês do professor: 2 feitos no Power Point, um feito com o software: elo (Ensino de Línguas on Line) com um texto em inglês onde o aluno acessa a literatura universal que é um trecho da Odisseia de Homero e 2 jogos feitos com material reaproveitável (palavra cruzada e um quebra cabeça feito com cilindro). Todo o material foi adaptado ao conteúdo do livro com diversos conteúdos em inglês com gramática e vocabulário. Os jogos de diversão e aprendizagem, envolvendo alunos em grupos com engajamento, competitividade e interação foi realizado e ao término, em cada turma selecionada, foi feita uma enquete para verificar o nível de satisfação dos alunos em relação aos jogos aplicados. A pergunta desta enquete era bem básica: Qual seu nível de satisfação com relação a estes jogos abaixo, e ao lado da descrição de cada jogo eles tinham que atribuir notas: 0 (ruim), 1 (regular), 2 (bom) e 3 (ótimo).

Imagem 1: elo (ensino de Línguas on-line) trecho do Quadrinho: Odisseia.

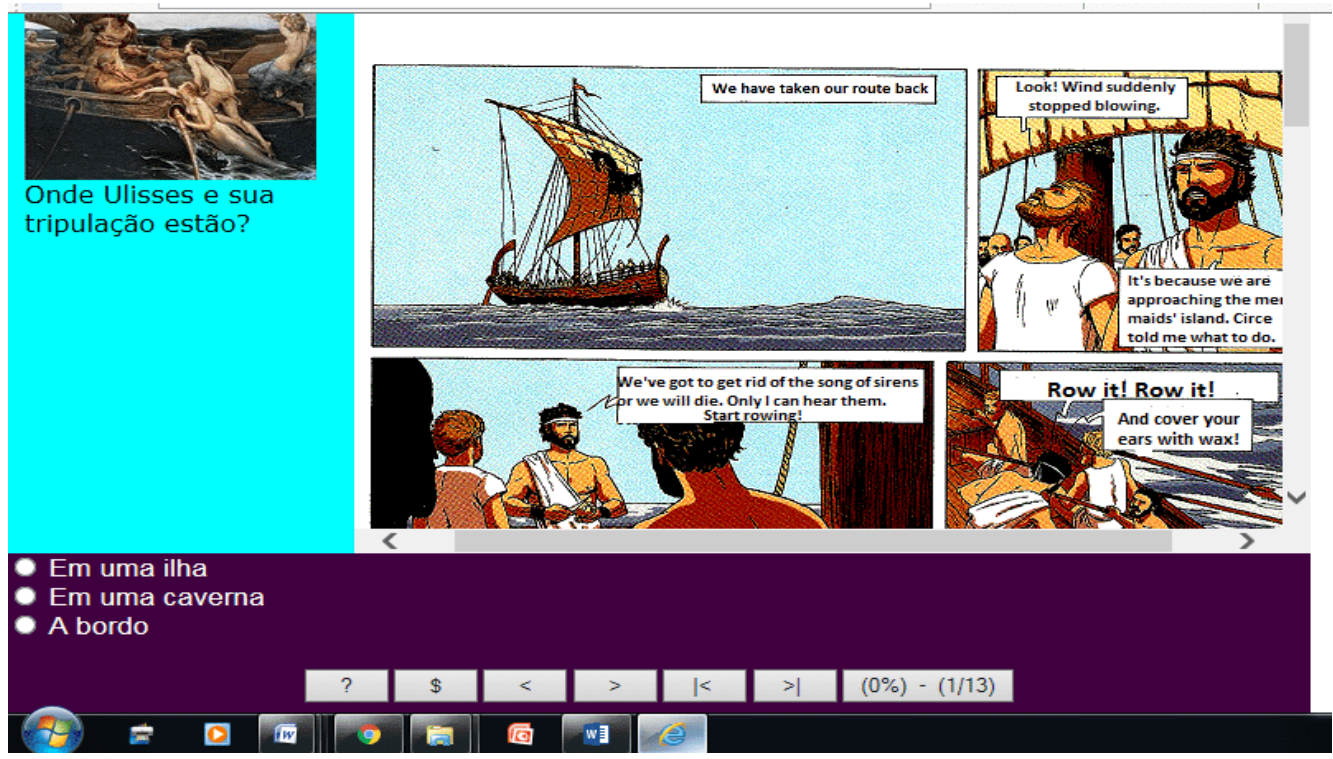

Fonte: Costa (2019)

Disponível em: https://www.nucleodoconhecimento.com.br/educacao/aprendizagemmultidisciplinar 
Imagem 2: Jogo no Power Point de seleção de letras feito com os 6ํanos. Conteúdo: Graus de parentesco.

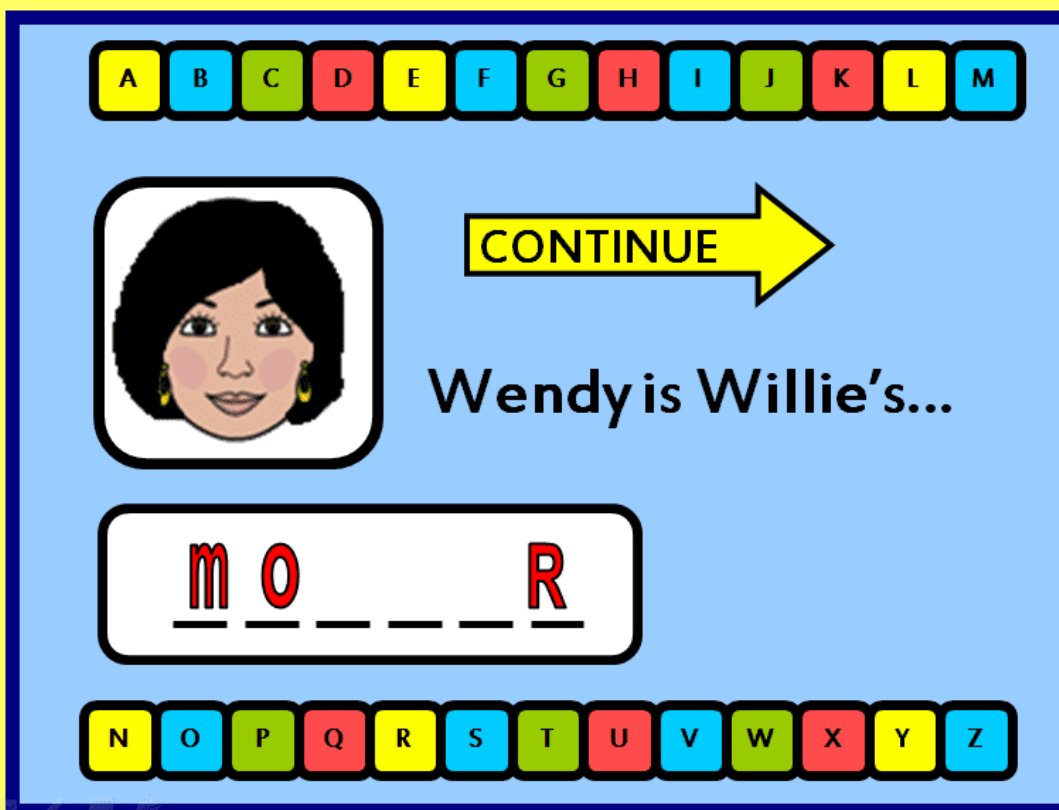

Fonte: Costa (2019)

Imagem 3: Cilindros para formar frases

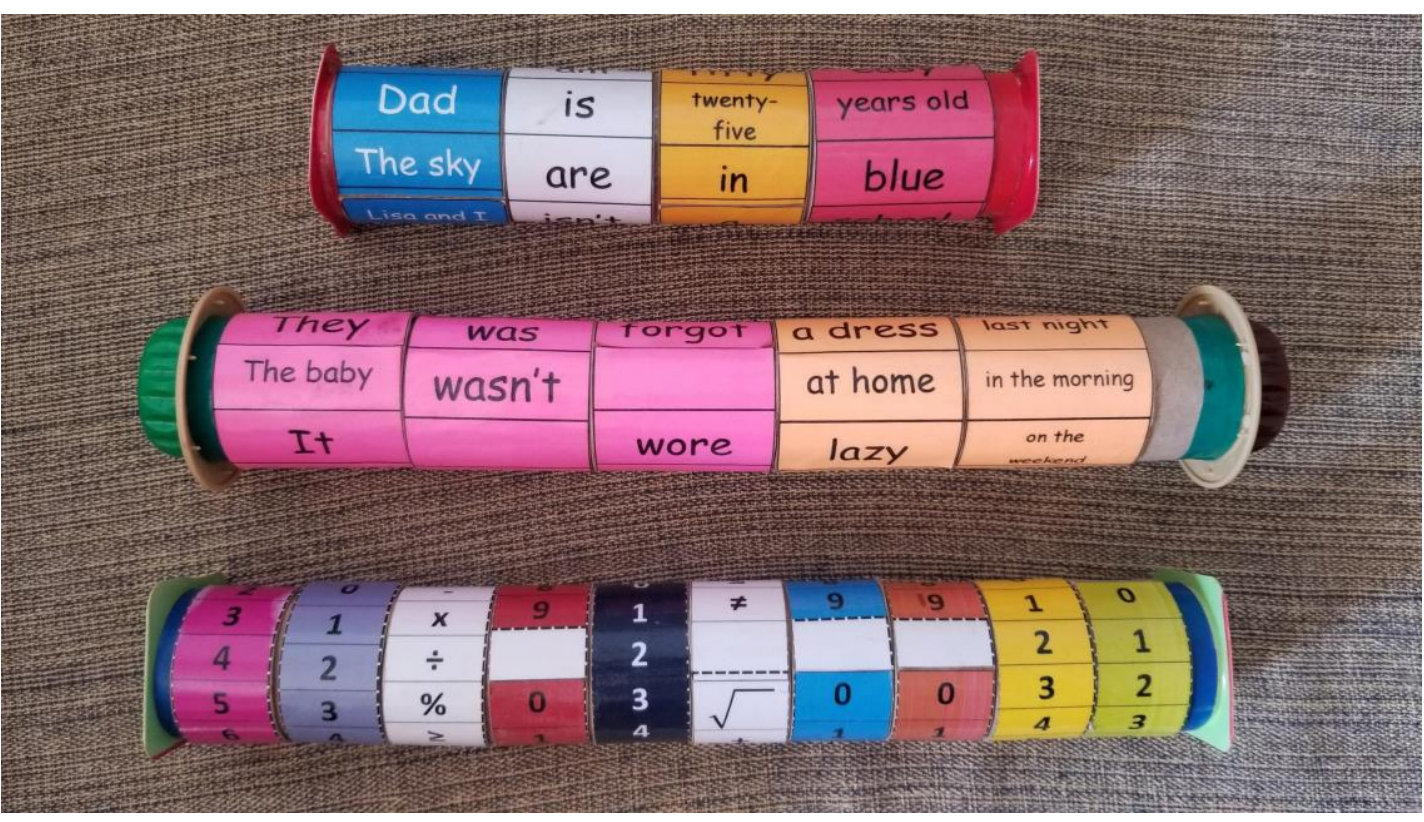

Fonte: Costa (2019)

RC: 59348

Disponível em: https://www.nucleodoconhecimento.com.br/educacao/aprendizagem$\underline{\text { multidisciplinar }}$ 


\section{CONHECIMENTO https://www.nucleodoconhecimento.com.br}

Imagem 4: Criando frases com os tubos

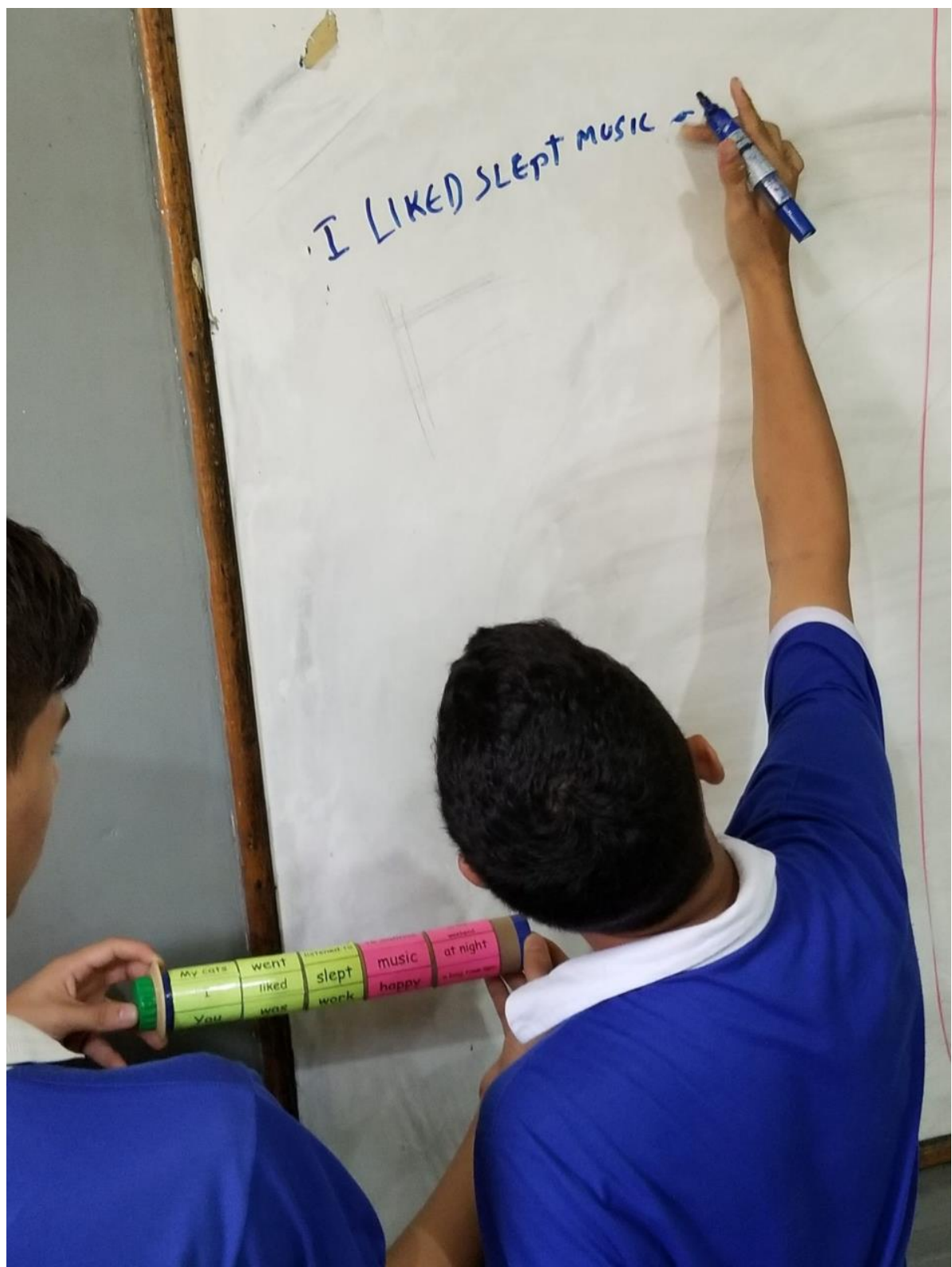

Fonte: Costa (2019)

\subsection{RESULTADO DA ENQUETE}

Verificou-se que pelo resultado da pesquisa feita em 4 turmas de $6^{\circ}, 7^{\circ}, 8^{\circ}$ e $9^{\circ}$ anos, que de 102 alunos, 60 acharam as atividades feitas em sala ótimas, 22 acharam boas, 11 regular e apenas um aluno não apreciou o jogo realizado o que mostra uma grande 
preferência dos alunos em acessar jogos durante as aulas regulares. Este relatório foi feito nessas turmas em uma escola com cerca de 740 alunos matriculados, usando um jogo no Power Point para cada os $6^{\circ}$ e $7^{\circ}$ anos, dois jogos no software elo para os $8^{0}$ e 9o anos, um jogo manual feito com um cilindro para formação de frases no passado simples feito com o $8^{\circ}$ ano e um jogo de palavras cruzadas sobre cores em inglês feito em um tabuleiro de MDF feito com o $6^{\circ}$ ano. $O$ gráfico abaixo apresenta os resultados:

Gráfico 1

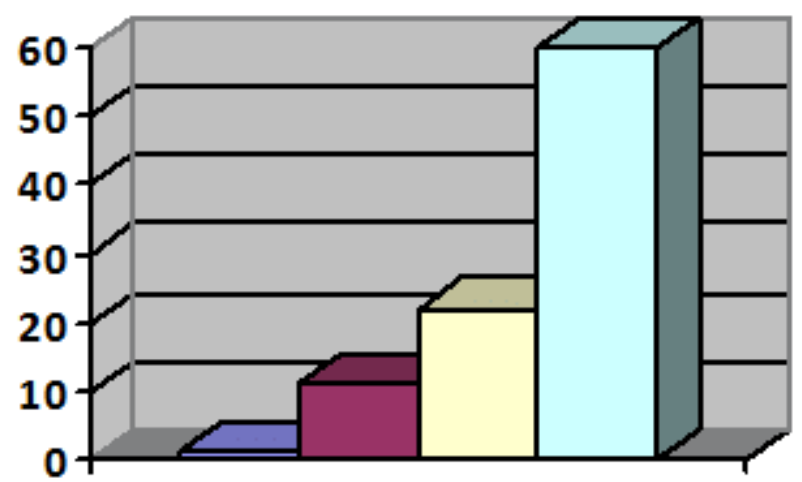

PESQUISA DE SATISFAÇÃO REALIZADA

\begin{tabular}{|l|}
\hline$\square$ RUIM \\
$\square$ REGULAR \\
$\square$ BOM \\
$\square$ ÓTIMO \\
\hline
\end{tabular}

COM OS 6, 7, 8 E 9 ANOSDO ENSINO FUNDAMENTAL

Fonte: Costa, 2019

\subsection{O QUE FOI FEITO COM A ENQUETE}

Após a constatação que os jogos foram considerados pela maioria ótimos, verificouse aqui um bom material para formular um plano de pesquisa para apresentar em uma Feira de Iniciação Científica na Cidade de Igarapé Miri, no estado do Pará, a FEICITI. Pensou-se em levar o material em inglês para esta feira, visando a oportunidade de criar jogos junto com as alunas surdas para que elas também pudessem apresentar um trabalho e interagir com o público. 


\subsection{A HORA DA INCLUSÃO}

As alunas surdas selecionadas, já contribuíram com um outro projeto que desenvolvido voltado para a robótica e educação ambiental, sendo destaques na apresentação destes trabalhos em outras feiras de ciência e tecnologia, onde foram premiados. Pensou-se, então, que elas poderiam apresentar um jogo que chamaria a atenção do público, incluindo os avaliadores, para que aprendessem libras. Assim, foi adaptado fotos de sinais em libras com o conteúdo do jogo em Power Point, algo que não é pensado dentro de sala de aula onde estes alunos passam uma boa parte do seu dia:

É necessário enfatizar que o sistema escolar, altamente marcado pela busca de homogeneização linguística e cultural, coloca às margens parte significativa dos alunos provenientes de grupos sociais desprestigiados, como os surdos, que fazem uso de repertórios linguísticos distanciados das práticas escolarizadas elitistas" A escola constrói este movimento, mas não inclui realmente este aluno surdo que tem um potencial muitas vezes maior do que o de alunos ouvintes (SILVA e SANTOS, 2017, p.297).

Desta forma, a partir das inquietações de professores orientadores, alunos ouvintes, alunas surdas, vislumbrou-se a possibilidade e defender um trabalho onde o aluno ouvinte defenderia o trabalho onde jogos digitais poderiam ser apresentados como meio interativo de experiência já vivida em sala de aula, adaptado ao livro didático e conteúdo em Libras, mostrando a possibilidade de pessoas aprenderem esta linguagem de maneira lúdica e interativa, esquivando-se mais desta homogeneização linguística e cultural, marcada pela exclusão deste grupo. Porém, precisava-se constatar o levantamento da pesquisa, interagindo com um público ainda maior e tentar obter o reconhecimento da comunidade científica que este trabalho poderia ser relevante para o contexto escolar. Então consolidou-se a participação de alunas surdas em um contexto científico, dotadas de suas especificidades e seu engajamento na resolução de um problema a ser apresentado ao público com incentivo e mediação dos professores orientadores. 


\subsection{NOVO PROJETO, NOVOS DESAFIOS}

Considerando a experiência destes alunos em apresentar trabalhos de cunho científico e tecnológico, já que "Fazer um projeto é lançar ideias para frente, é prever as etapas de um trabalho, é definir aonde se quer chegar" (BAGNO, 2007) vislumbrou-se novos desafios para um novo projeto que propunha o uso de jogos para mostrar ao público que jogar é um hobby, e que pode ser prazeroso quando usado para aprender. Aprofundando-se neste aspecto da brincadeira, do jogo, justificando que os animais brincam, por isso como mamíferos, faz-se necessário também brincar, definir estratégias, jogar uns com os outros, competir, mas sabiamente, conhecendo as regras do jogo. Pesquisou-se os efeitos dos jogos o cérebro: qual a sensação que eles proporcionam, o que é possível sentir ao jogar.

\subsection{A EXPOSIÇÃO AO PÚBLICO; ENSINANDO O QUE FOI APRENDIDO}

Ao interagirem com o público durante a FEICITI, constatou-se que a presença dos jogos: manuais ou digitais adaptadas ao material didático para o ensino de inglês, libras ou qualquer outra disciplina, fazem a grande diferença na aprendizagem: os visitantes competiram uns com os outros durante as apresentações, sentindo um grande entusiasmo em jogar, com vibração, sentimento de recompensa, frustração, enfim, todas as emoções causadas por substâncias químicas liberadas pelo cérebro. Os alunos observaram este mix de emoções porque eles também jogam e puderam, como cientistas, informar para os visitantes: "veja, é assim que o seu cérebro reage a este dispositivo e causa esta sensação em você". É o que chamamos de sentir na pele estas emoções que todos têm em comum, principalmente a geração $Z$, ligada às novas tecnologias. Entretanto, é preciso ter cautela ao jogar aqueles jogos como: Free Fire, World War Craft e outros que tiram as noites de sono e fomenta a necessidade de jogar mais e sentir ainda mais necessidade de ter a recompensa, ou a dopamina, que já mencionamos. 
Esta ponderação que levantamos, a dos jovens jogarem com mais cautela e a possibilidade de professores que nos assistiram, adaptarem jogos ao seu material didático fez o projeto ser bem sucedido. As alunas surdas perceberam isso também de forma muito clara e o protagonismo delas ficou em evidência. Como resultado disso, os avaliadores elegeram o projeto como o melhor em ciências humanas e ainda nos credenciaram para a FECEAP, junto com outro projeto que apresentamos simultaneamente durante a FEICITI.

Imagem 5 - Jogo feito no Power Point para as alunas surdas ensinarem libras durante a FEICITI

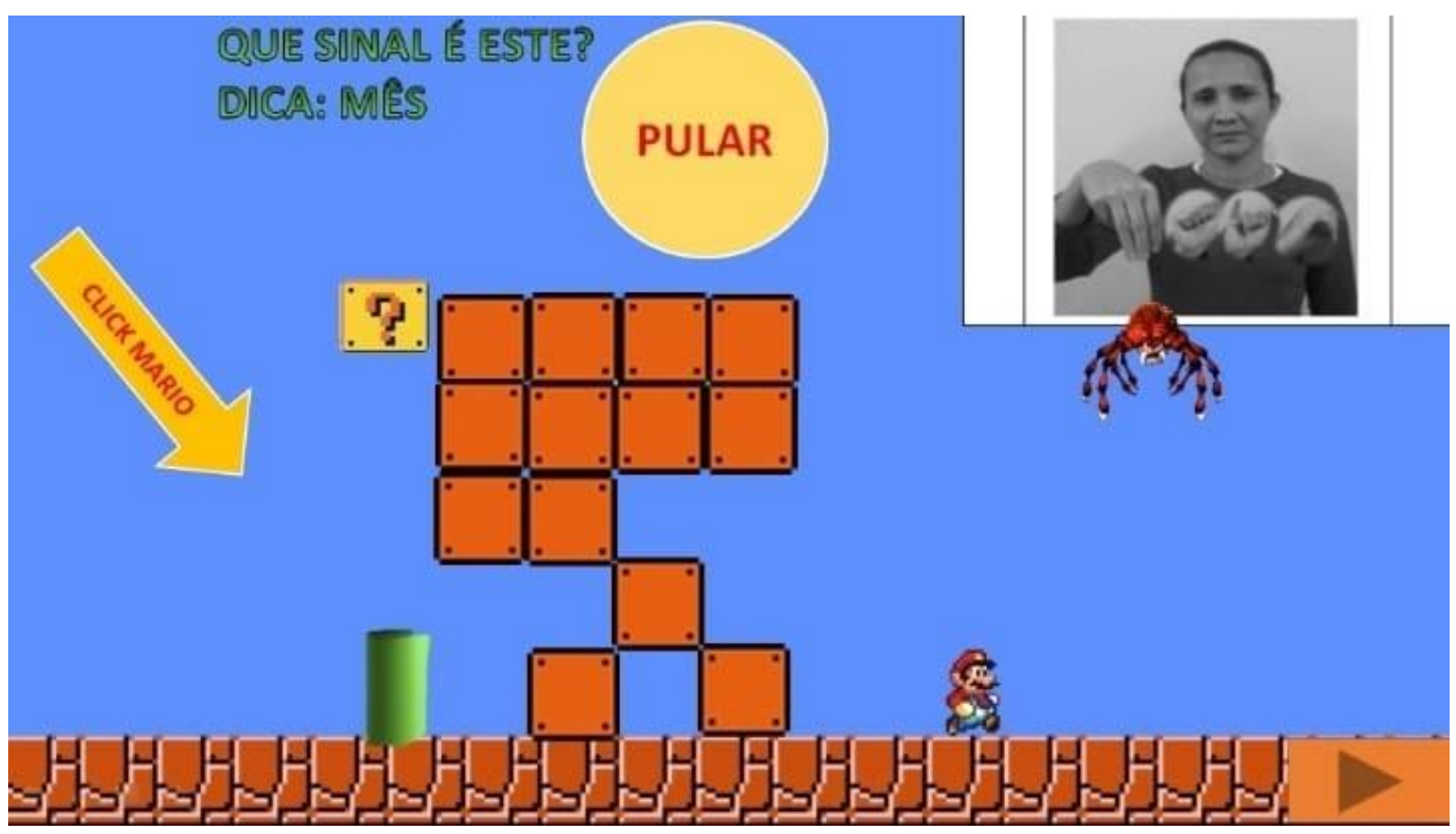

Fonte: Costa (2019) 
Imagem 6 - aluno $O$ aluno ouvinte Marcos Pantoja e Juliene Taissa apresentando o projeto durante a FEICITI.

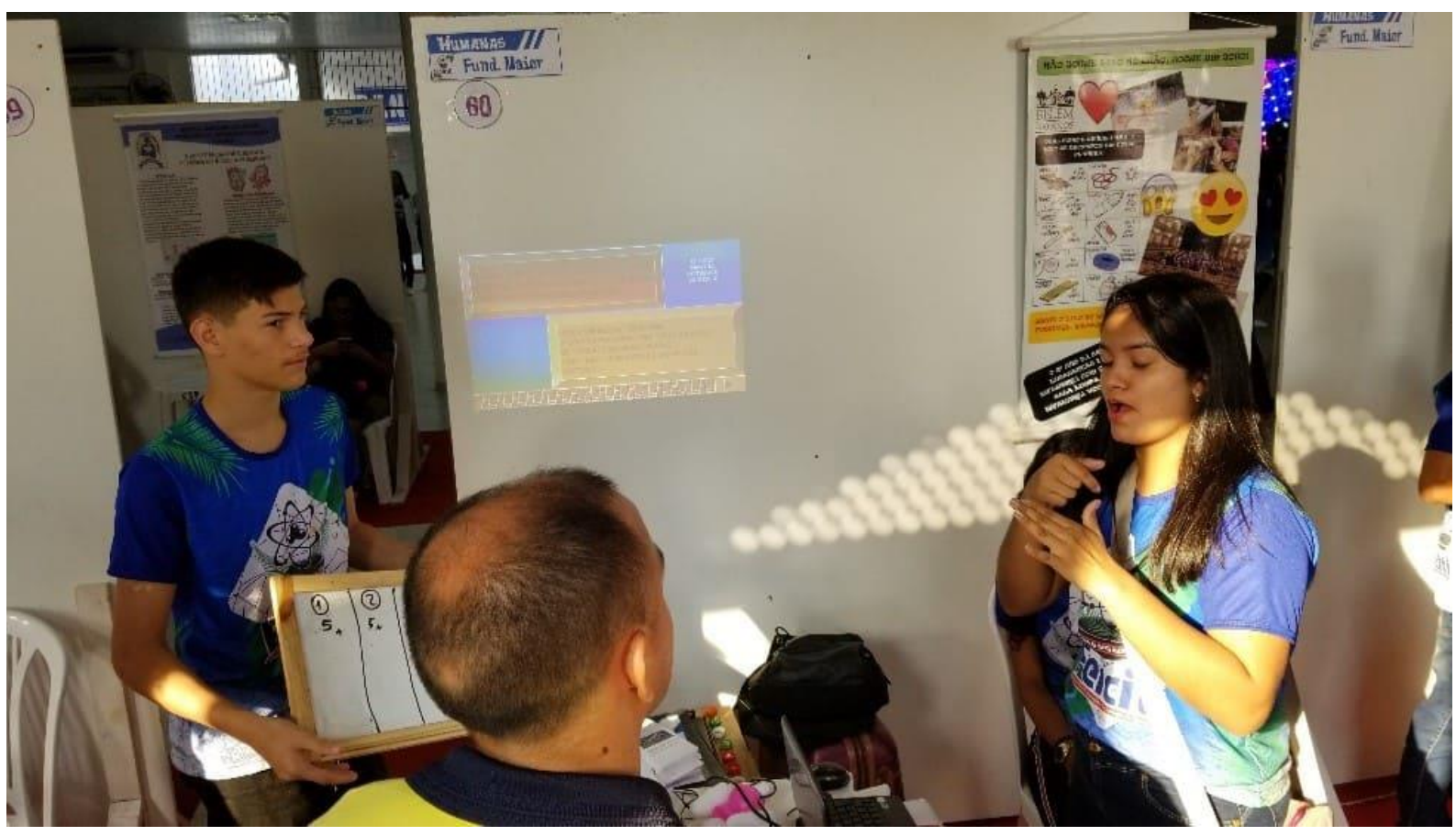

Fonte: Costa (2019)

\section{CONSIDERAÇÕES FINAIS}

Constatou-se, pela verificação de dados e experiência durante todo o desenvolvimento do projeto, que é indubitável e imensurável, o potencial que alunos especiais podem desenvolver aos olhos de seus tutores e/ou professores. Percebeuse isto com muita clareza durante todo o processo de criação do projeto. No Art. $11^{\circ}$ É instituída a Lei Brasileira de Inclusão da Pessoa com deficiência na qual destina-se a promover condições de igualdade visando a inclusão social e a cidadania e espera-se isso no ambiente escolar, mas que tipo de inclusão é feita realmente? Quem se habilita a aplicar o sociointeracionismo de Vygotsky e juntar alunos especiais e não especiais para atingir um determinado fim? O projeto REUSETECH Gamer mostrou que é possível incluir e fazer o aluno com deficiência sentir-se incluído, o que é ainda mais relevante. 
Um outro ponto que vale a pena ressaltar é o da desmotivação de professores em desenvolver projetos que façam os alunos aparecerem. Obviamente as justificativas são inúmeras para que os profissionais em educação não criem um movimento que dê a mão aos alunos, que vai desde os baixos salários até o comodismo e própria falta de motivação. Ou ainda, a visão de que o aluno deve continuar a ser dependente do professor com pouca ou sem nenhuma autonomia, já contestada e superada por diversos autores. Se respeitarmos a classificação de Antunes (2012), por muito tempo, acreditou-se que todo processo de ensino se fixava no figura do professor. Esta concepção, atualmente, está inteiramente superada. Entretanto, o que muitos professores podem fazer é extrair o mínimo até chegar ao máximo de cada aluno, os vendo como seres que podem ter mais autonomia em aprender, pois este é o nosso principal propósito como professores: prepará-los para a vida, para os novos desafios e com projetos, como este que criamos, pode-se fazê-los ampliar ainda mais a percepção de mundo em um curto espaço de tempo.

Pelos resultados da pesquisa e pelo resultado do trabalho premiado em uma Feira de Ciência e Tecnologia, pontua-se que os alunos precisam de mais interação em sala de aula, sem ou com algum tipo de deficiência, além disso, incluir a competição saudável. Após a apresentação do trabalho, o aluno ouvinte Marcos Pantoja foi capaz de compreender as 4 habilidades da língua inglesa: Speaking, Listening, Writing e Reading, aprendeu a usar o conhecimento prévio, fazer inferências ou suposições, soube como correr riscos, desafiou os visitantes, foi desafiado, e entendeu também que na situação de jogo, precisa-se saber lidar com a derrota e não acumular frustrações, e ter um sentimento de pertencimento à escola, que já pode ser vista por ele e outros alunos como um espaço de conhecimento, descobertas e proatividade. As alunas surdas do projeto perceberam que elas podem se dedicar a pesquisa, buscar opções de convívio com pessoas que não sejam só surdas e mostrar à diversas pessoas a diversidade pela inclusão, que é essa que mostra quem o aluno com deficiência é, sem mascarar sua condição. E quando os alunos são instigados a decidir que rumo tomar em seu trabalho, a aprendizagem torna-se mais significativa, leva-os a patamares mais elevados com intuito de aprender e engajarem-se no 
processo de aprendizagem. Não esquecendo que o papel do professor como mediador durante processo é fundamental para este engajamento dos alunos e o resultado final esperado.

\section{REFERÊNCIAS}

ALVES, Flora. Gamification: como criar experiências de aprendizagem engajadoras: um guia completo do conceito à prática. 1. ed. São Paulo: DVS, 2014.

ANTUNES, Celso. As inteligências múltiplas e seus estímulos. 17. ed. Campinas: Papirus, 2012.

BAGNO, Marcos. Pesquisa na Escola: o que é e como se faz. 21. ed. São Paulo: Loyola, 2007.

NOGUEIRA, Nilbo Ribeiro. Pedagogia dos projetos: etapas, papéis e autores. 4. ed. São Paulo: Ética, 2008.

ROCHA, Claudia Hilsdorf. et al. Diálogos sobre tecnologia educacional: Educação linguistic, mobilidade e práticas translingues. Campinas: Pontes, 2017.

SANCHO, Juana Maria et al. Tecnologias para transformar a educação. Trad. Valério Campos. Porto Alegre: Artmed, 2006.

TONÉIS, Cristiano. Os games na sala de aula: Games na educação ou gamificação na educação? São Paulo: Bookess, 2017.

Enviado: Janeiro, 2020.

Aprovado: Agosto, 2020. 